Document downloaded from:

http://hdl.handle.net/10251/156841

This paper must be cited as:

Dalmau, ME.; Eim, V.; Rosselló, C.; Carcel, JA.; Simal, S. (2019). Effects of convective drying and freeze-drying on the release of bioactive compounds from beetroot during in vitro gastric digestion. Food \& Function. 10(6):3209-3223. https://doi.org/10.1039/c8fo02421a

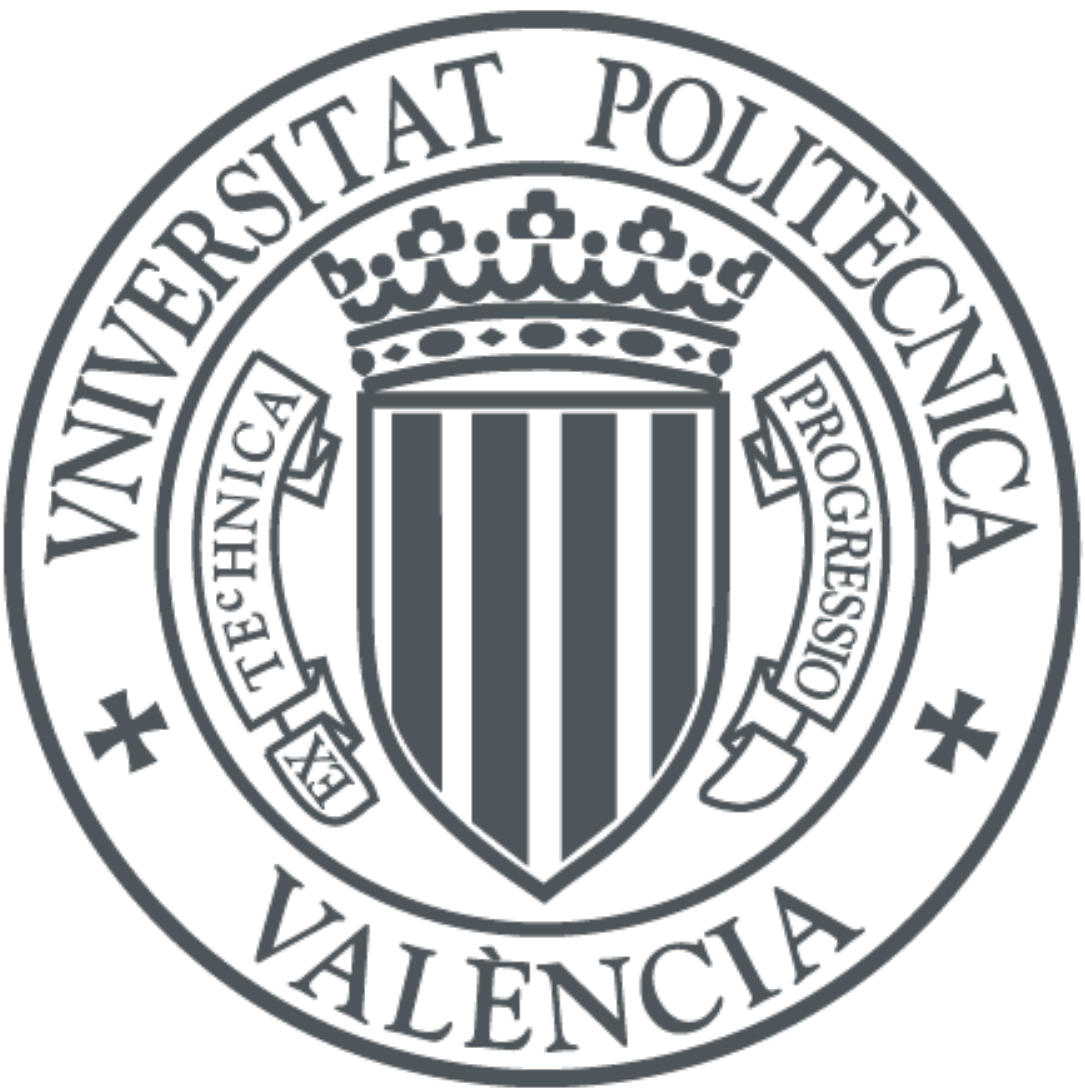

The final publication is available at

https://doi.org/10.1039/c8fo02421a

Copyright The Royal Society of Chemistry

Additional Information 


\title{
Effects of convective drying and freeze-drying on the release of bioactive compounds from beetroot during in vitro gastric digestion
}

\author{
Maria Esperanza Dalmau, (iD) Valeria Eim, Carmen Rosselló, Juan A. Cárcel and \\ Susana Simal*
}

Drying may alter the microstructure of vegetables and influence the release of bioactive compounds during digestion. The effects of convective drying (at $60{ }^{\circ} \mathrm{C}$ and $2 \mathrm{~m} \mathrm{~s}^{-1}$; CD) and freeze-drying (at $-50^{\circ} \mathrm{C}$ and $30 \mathrm{~Pa}$; FD) on the microstructure (evaluated using scanning electron microscopy (SEM) and image analyses with ImageJ software) of beetroot and the kinetics of biocompound release (total polyphenol content (TPC) and antioxidant activity (AA)) during $180 \mathrm{~min}$ of in vitro gastric digestion have been studied. Raw beetroot was used as the control. Drying promoted the collapse of cell walls causing volume shrinkage that resulted in a greater cell number per area unit; meanwhile in vitro digestion caused cell structure disruption, which resulted in a lower cell number per area unit. Drying promoted decreases of TPC $(42 \%$ in CD and $29 \%$ in FD) and AA (66\% in CD and 63\% in FD) of beetroot. However, release of TPC and AA from dried samples during digestion was $82 \%(C D)$ and 76 (FD) \% higher than from the raw sample. The Weibull model allowed the satisfactory modelling of the TPC and AA release kinetics (mean relative error of simulation lower than $8.5 \%$ ).

\section{Introduction}

Beetroot is a cultivated form of Beta vulgaris subsp. vulgaris (conditiva) and describes a number of varieties of edible taproots that are grown throughout America, Europe, and Asia. ${ }^{1}$ In recent years, the root vegetable Beta vulgaris L. has attracted significant attention as a health-promoting functional food product. $^{2}$ This scientific interest has arisen because of the composition of its various nutrients. Beetroot is rich in valuable active compounds such as carotenoids, betalains, polyphenols and flavonoids, and saponins. ${ }^{3-5}$ The high concentration of antioxidant substances called betalains has beneficial effects on human health, including stimulation of the immune and hematopoietic systems, and anti-inflammatory, antitumor, and hepatoprotective properties. ${ }^{6}$

Beetroot is a seasonal product; thus, drying is an alternative for consumption during the off-season. Drying is one of the most widely used methods for food preservation, its main objective being to remove water from food in order to prevent microbial spoilage and deterioration reactions. ${ }^{7}$ Moreover, smaller spaces are needed for storage and lighter weight for transportation. The drying method applied may affect the colour, shape, structure, and nutritional and nutraceutical components in various ways, therefore, it is very important to find an optimal drying temperature and rational heat dosage. ${ }^{8}$

Convective and freeze-drying are two methods among the several that exist. On the one hand, convective drying is the most common drying method, which consists of removing water with air, via simultaneous heat, mass and momentum transfer. The required heat is conducted to the food by a stream of air. The energy is transferred to the surface of the product by convection and from there, enters by different mechanisms, depending on the product structure. This heat flux causes a product temperature increase and water evaporation. ${ }^{9,10}$ Convective drying can have a negative impact on the physico-chemical properties of vegetables. ${ }^{4}$ On the other hand, freeze-drying is one of the most preferred drying techniques for high-quality products, partially because of its ability to yield highly porous microstructures that contribute to the high rehydration capacity of the freeze-dried foods. ${ }^{11}$ In freeze-drying, food is initially frozen to induce water crystallization and it is subsequently dehydrated by sublimation of the ice and desorption of the unfrozen water. It is also known that freeze-drying demands significant energy consumption.

The quality of the dried products is usually characterized by their flavor, aroma and nutrient retention as well as cellular structure, texture and reconstitution properties. To see the 
effect of processing on the cellular structure of food generally requires microscopic examination. The light microscope is the principal tool, but confocal microscopy, electron microscopy, atomic force microscopy, magnetic resonance or computer tomographic imaging, among other methods, can be also used for different purposes. The image that these techniques generate is usually digitized and analyzed using computer technology. Measurement of the image characteristics to obtain microstructural information can be efficiently carried out using different analysis techniques. Among the different types of image texture analysis, that of statistical texture is one of the most widely used in the food industry for its high accuracy and shorter computation time. This methodology analyzes the gray spatial distribution and derives a set of statistics from the distributions of local characteristics. ${ }^{12}$

On the other hand, in vitro digestion could be used to assess the effect of processing on the release of nutrients. In vitro digestion assays simulate the physiological conditions of digestion in vivo and are useful tools for studying and understanding changes, interactions, as well as the bioaccessibility of nutrients. ${ }^{13}$ Paustenbach (2000) defined the bioaccessibility of a substance as the fraction that is soluble in the gastrointestinal environment and is available for absorption. ${ }^{14}$ The application of in vitro simulated digestion has demonstrated that food components or food matrices have different effects on bioactive compounds, and, in some cases, only a minor fraction of the total quantity of these compounds in foods is potentially bioaccessible. ${ }^{15,16}$ In the present study, the release of compounds during the gastric phase will be evaluated.

Thus, the objective of this study was to evaluate the effects of two different drying methods (convective and freeze-drying) on the cellular matrix of beetroot (Beta vulgaris) and on the release of its bioactive compounds during in vitro gastric digestion.

\section{Materials and methods}

\subsection{Samples}

Beetroot (Beta vulgaris var. conditiva) was purchased from a local supermarket (initial moisture content of $6.67 \pm 0.04 \mathrm{~g} \mathrm{~g}^{-1}$ $\mathrm{dm}$ and total soluble solids of $10.8 \pm 0.4^{\circ} \mathrm{Brix}$ ). It was stored at $4{ }^{\circ} \mathrm{C}$ for a maximum of one week before processing. Cubes were cut $(0.01 \mathrm{~m}$ edge $)$ from the central parts of the beetroot tissue, not including the peel, and immediately processed.

\subsection{Convective-drying- and freeze-drying processes}

Convective drying (CD) was carried out in a laboratory-scale hot air dryer previously described, ${ }^{17}$ operating at $60{ }^{\circ} \mathrm{C}$ with an air velocity of $2 \mathrm{~m} \mathrm{~s}^{-1}$. Samples were dried to a final moisture content of $0.17 \pm 0.03 \mathrm{~g}$ water per $\mathrm{g} \mathrm{dm}$.

Freeze-drying (FD) of the cubes was carried out in a freezedrier (Telstar LyoQuest, Barcelona) operating at $-50{ }^{\circ} \mathrm{C}$ and a vacuum pressure of $30 \mathrm{~Pa}$, to a final moisture content of $0.07 \pm$ $0.01 \mathrm{~g}$ water per $\mathrm{g} \mathrm{dm}$.
Before in vitro digestion, $\mathrm{CD}$ and $\mathrm{FD}$ samples were rehydrated by immersion in distilled water $(25: 100$ ( $\mathrm{g}$ beetroot per $\mathrm{ml}$ water)) at $37^{\circ} \mathrm{C}$ until they reached a final moisture content similar to that of the raw samples $\left(6.67 \pm 0.04 \mathrm{~g} \mathrm{~g}^{-1} \mathrm{dm}\right)$ (approx. 90 and $80 \mathrm{~min}$, respectively).

\subsection{In vitro digestion procedure}

The beetroot samples were digested following the in vitro gastric digestion method reported by Bornhorst and Singh. ${ }^{18}$ Briefly, simulated saliva was prepared with $1.000 \mathrm{~g}^{-1}$ mucin, $2.000 \mathrm{~g} \mathrm{l}^{-1} \alpha$-amylase (1500 $\mathrm{U} \mathrm{ml}^{-1}$ ), $0.117 \mathrm{~g} \mathrm{l}^{-1} \mathrm{NaCl}, 0.149 \mathrm{~g}$ $1^{-1} \mathrm{KCl}$ and $2.100 \mathrm{~g}^{-1} \mathrm{NaHCO}_{3}$ solution at $\mathrm{pH}$ 7.0. Simulated gastric juice was prepared with $1.000 \mathrm{~g}^{-1}$ pepsin $(25000$ $\mathrm{U} \mathrm{ml}^{-1}$ ), $1.500 \mathrm{~g}^{-1}$ mucin, and $8.780 \mathrm{~g}^{-1} \mathrm{NaCl}$, mixed in deionized water at a $\mathrm{pH}$ of 1.8-2.0. All solutions were prepared daily.

The beetroot cubes ( $c$. $200 \mathrm{~g}$ ) were mixed with $80 \mathrm{ml}$ of simulated saliva for $30 \mathrm{~s}$, followed by immersion in $800 \mathrm{ml}$ of simulated gastric juice previously heated to $37{ }^{\circ} \mathrm{C} .{ }^{18}$ The mixture was incubated in a shaking water bath (Unitronic 320 OR, Selecta, Spain) at $37^{\circ} \mathrm{C}$ and $100 \mathrm{rpm}$ for up to $3 \mathrm{~h}$. Sequential samples were taken initially (no digestion), $30 \mathrm{~s}$ after mixing with saliva, and after 10, 20, 30, 45, 60, 90, 120, $180 \mathrm{~min}$ and then $24 \mathrm{~h}$ of gastric digestion, in triplicate, assessing moisture, acidity, total polyphenol content (TPC) and antioxidant activity (AA); and also, initially (no digestion) and after $180 \mathrm{~min}$ of gastric digestion, for microstructural analyses. Sequential samples of gastric juice were taken in triplicate, after 10, 20,30, 45, 60,90, 120, $180 \mathrm{~min}$ and $24 \mathrm{~h}$ of gastric digestion for total polyphenol content (TPC) and antioxidant activity (AA) analyses.

All digestion experiments were performed at least in triplicate, and results were expressed on an initial dry matter basis $\left(\mathrm{dm}_{\mathrm{o}}\right)$ to better compare the different samples.

\subsection{Microstructural analyses}

2.4.1. Scanning electron microscopy (SEM). Cell walls of raw and dried beetroot before (CD and FD samples) and after (raw180, CD180 and FD180) 180 min of in vitro gastric digestion were observed using scanning electron microscopy (SEM). For SEM observation, samples were soaked in liquid nitrogen in order to be cut with a sharp razor blade and freeze-dried. Gold coating was performed using a Bio-Rad E-5400 sputter coater (Polaron, UK) (10-4 mbar, $20 \mathrm{~mA}, 80 \mathrm{~s})$. Samples were then observed in an S-3400N Hitachi SEM (Germany), accelerated at $15 \mathrm{kV}$ and under a vacuum pressure of $40 \mathrm{~Pa}$.

2.4.2. Image analysis. Scanning electron microscope photographs were analyzed using an automatic image processing method with ImageJ 2.0.0 software (Creative Commons license). The images were calibrated by the application "Set scale" of the same software. Subsequently, the images were transformed to a binary image. Finally, the images were analyzed with the application "Analyze particles" of the software. ${ }^{19}$ To establish a representative structural analysis, fifteen scanning electron microscope photographs of each sample were analyzed. 
The percentile profile of cell areas and the cell number per unit of tissue surface of each sample were calculated using the "prctile" function of Matlab 2017b software (The Mathworks Inc., USA).

\subsection{Chemical analyses}

The moisture content of all beetroot samples was determined according to the AOAC official method no. 934.06 (AOAC, 1997) and expressed in $g$ water per $g$ initial dry matter $\left(\mathrm{dm}_{\mathrm{o}}\right)$. The acidity of the samples was determined according to the AOAC official method no. 942.15 (AOAC, 1998) and expressed in malic acid equivalent/100 $\mathrm{g}$ of initial dry matter $\left(\mathrm{dm}_{\mathrm{o}}\right)$.

To determine the total polyphenol content (TPC) and the antioxidant activity (AA), methanol extracts from the samples were prepared according to the methodology described by Eim et $a l^{20}$ with minor modifications. Samples were accurately weighed $(\sim 2.0 \mathrm{~g})$, and $20 \mathrm{ml}$ of methanol $(\mathrm{MeOH})$ extraction solvent was added. The mixtures were homogenized using an Ultra-Turrax homogenizer (T25 Digital, IKA, Germany) at $13000 \mathrm{rpm}$ for $1 \mathrm{~min}$ at $4{ }^{\circ} \mathrm{C}$, and the solutions were refrigerated overnight. They were centrifuged at $2700 \mathrm{~g}$ for $10 \mathrm{~min}$ followed by filtration, and then refrigerated at $4{ }^{\circ} \mathrm{C}$ until analysis. Gastric juice samples were analyzed directly without further extraction.

Total polyphenol content (TPC) was determined by means of the Folin-Ciocalteu assay according to Eim et $a l^{20}$ Antioxidant activity (AA) was determined using the ABTS (radical cation scavenging activity), FRAP (ferric reducing antioxidant power assay), and CUPRAC (cupric reducing antioxidant capacity) assays according to Gonzalez-Centeno et al. ${ }^{21}$ In all assays, absorbance measurements were carried out at $25{ }^{\circ} \mathrm{C}$ in an UV/Vis/NIR spectrophotometer (MultiSkan Spectrum, Thermo Scientific, Finland) and correlated with standard curves. TPC was expressed as mg gallic acid equivalent (GAE) per $g$ initial dry matter $\left(\mathrm{dm}_{\mathrm{o}}\right)$ and AA was expressed as $\mathrm{mg}$ Trolox per $\mathrm{g}$ initial dry matter $\left(\mathrm{dm}_{\mathrm{o}}\right)$ for beetroot. $^{22}$ The dimensionless release $(\Psi)$ of TPC and AA from beetroot cubes has been defined as indicated in eqn (1), and the dimensionless release measured in gastric juice $(\theta)$, is indicated in eqn (2); both are presented as a percentage.

$$
\begin{gathered}
\Psi_{1 / 4}^{1} \frac{C_{0}-C_{\mathrm{i}}}{C} \times 100 \\
\theta_{\substack{1 / 4 \\
\mathrm{D}}} \frac{C_{\mathrm{i}}}{C_{\max }} \times 100
\end{gathered}
$$

where $C_{0}$ is the initial concentration, $C_{\mathrm{i}}$ is the concentration at time $i$ and $C_{\max }$ is the maximum concentration released from the beetroot to the gastric juice (experimentally measured after $24 \mathrm{~h}$ of gastric digestion). All the analyses were performed in triplicate on samples from each digestion.

\subsection{Mathematical model}

Changes in total polyphenol content and antioxidant activity (ABTS, FRAP, and CUPRAC assays) at different times during in vitro digestion in both the beetroot matrix and the gastric juice were analyzed and fitted to the Weibull model (eqn (3)).

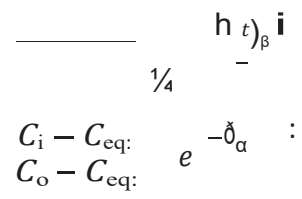

The equilibrium release, represented by $C_{\text {eq, }}$. was assumed to be equal to the experimental value after $24 \mathrm{~h}$ of in vitro digestion. ${ }^{21}$ The fitting parameters of the model were $\alpha$ and $\beta$. The $\alpha$ parameter can be related to the inverse of the change rate. As such, a lower $\alpha$ indicates a faster rate of change. The shape parameter $\beta$ represents a behavior index of the material during the process. ${ }^{23}$ When $\beta$ is equal to 1 , the model corresponds to a first-order kinetic with a constant input rate. ${ }^{20}$ However, when $\beta$ has a value above or below 1 , this parameter denotes the concavity (increasing change rate over time) or convexity (decreasing change rate over time) of the curve, respectively.

\subsection{Statistical analysis}

Statistical analyses were performed using R 3.1.0 software. Results are presented as mean values with their corresponding standard deviations. Parametric ANOVA and Tukey's tests were used to evaluate the existence of significant differences among samples (moisture content, TPC and results from image analysis). These statistical analyses were replaced by the KruskalWallis and pairwise-Wilcox (BH corrected) tests, when data were not normally distributed and/or showed heterogeneity of variances (AA measured using the ABTS, CUPRAC and FRAP methods). Differences at $p<0.05$ were considered significant.

The identification of the Weibull model parameters $\alpha$ and $\beta$ was carried out using the 'fitnlm' function of the optimization toolbox of MATLAB R2017 (The MathWorks Inc., USA), which estimates the coefficients of a nonlinear regression function and the residuals using the least number of squares. To determine the $95 \%$ confidence intervals (CI) and the standard error of the estimated parameters (SE), the 'coefCI' function and the covariance matrix were used, respectively. To statistically evaluate the accuracy of the proposed mathematical model and its capacity to simulate the experimental results and predict variations within the system, the mean relative error (MRE) (eqn (4)) was estimated by the comparison of experimental and simulated data. The lower the MRE, the better the fit provided by the model. ${ }^{24}$

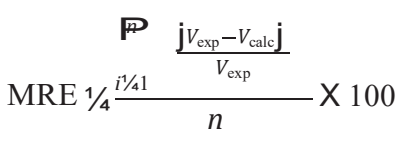

ð४

where $V_{\text {exp }}$ and $V_{\text {calc }}$ are the experimental and calculated values and $n$ is the number of experimental data. 


\section{Results and discussion}

3.1. Changes in food matrix structure during in vitro gastric digestion

3.1.1. Microstructural images (SEM). The images of raw and processed samples before and after $180 \mathrm{~min}$ of in vitro gastric digestion are shown in Fig. 1. Fig. 1a 1 shows the microstructure of the raw sample prior to in vitro gastric digestion. Raw samples are composed of almost isodiametrical and polyhedral cells with few intercellular spaces, as was previously observed by Nayak et al. ${ }^{25}$ After 180 min of digestion (Fig. 1a2) a significant cell lysis was observed, resulting in a smaller
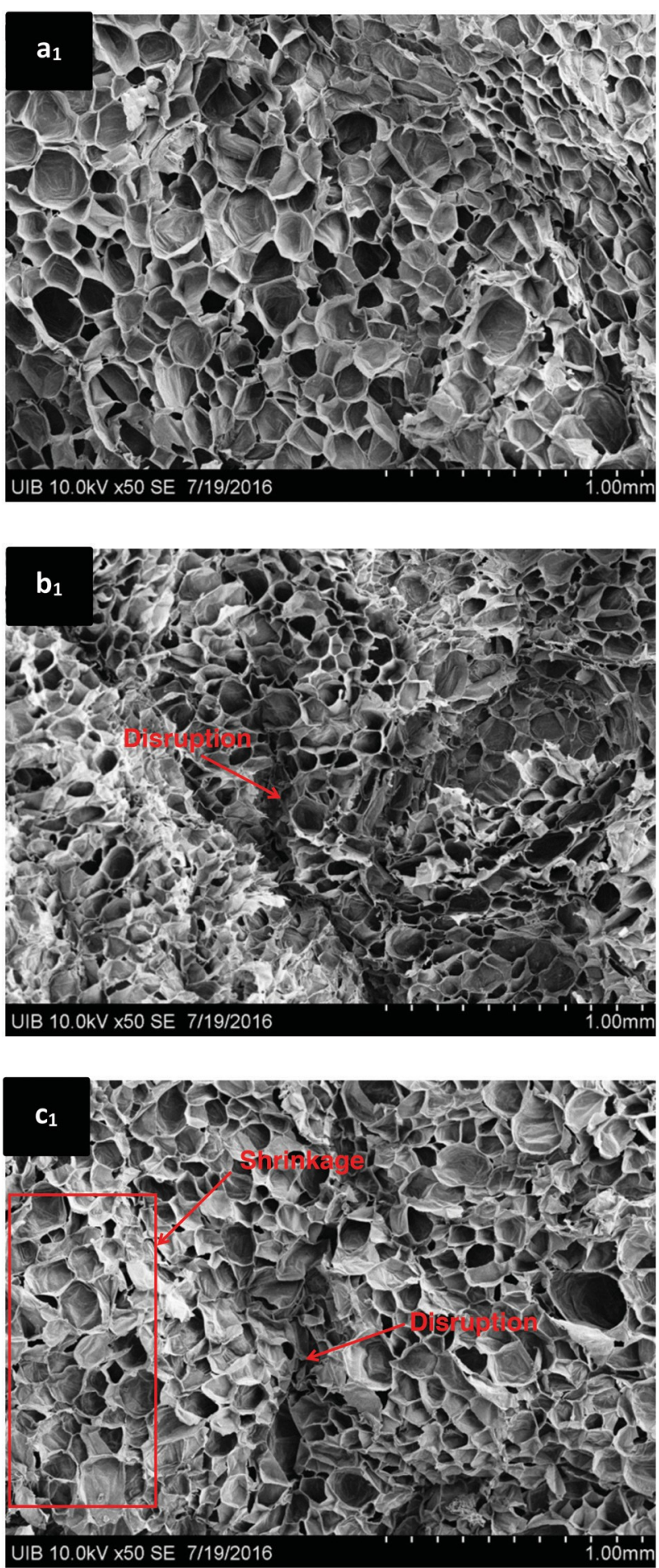
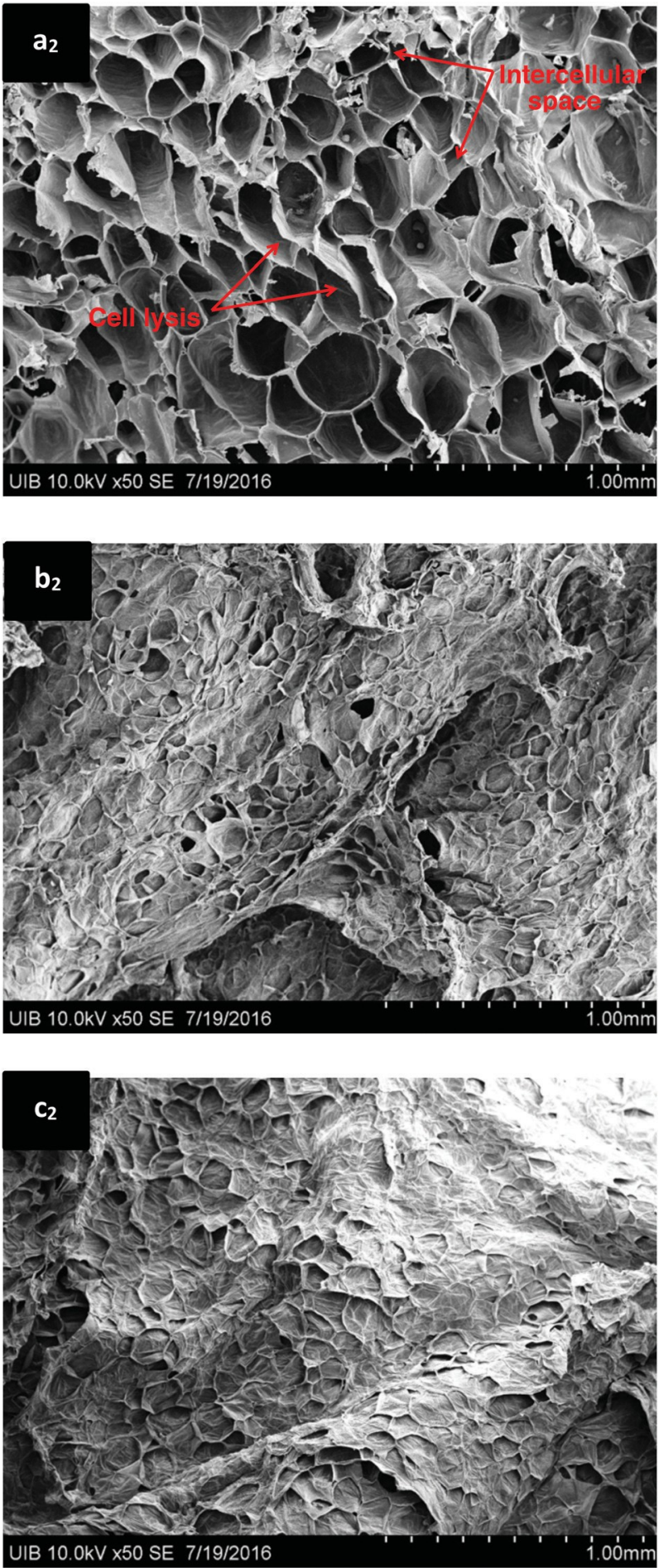

Fig. 1 SEM images of beetroot samples: a-Raw, b-CD and c-FD. 1-Before in vitro gastric digestion. 2-After 180 min of in vitro gastric digestion. 
number of cells per unit area along with increases in the intercellular space between remaining cells. Carnachan et $a l^{26}$ studied the microstructure of kiwi pulp after in vitro gastric digestion for $30 \mathrm{~min}$, followed by in vitro intestinal digestion by stirring for $120 \mathrm{~min}$. Similar to the current study, these authors observed an increase in the intercellular space after in vitro digestion.

Cell walls act as the main natural structural physical barriers governing biocompound release. Pectin composition and the presence of other polysaccharides in the cell wall influence the bioaccessibility of biocompounds by interacting differently with the target compounds. ${ }^{27,28}$ Moreover, a strong correlation between the physical state of the chromoplast substructures and the efficiency of biocompound release during digestion were found in previous studies. ${ }^{29-31}$ It has been observed ${ }^{32-34}$ that drying may alter the microstructure of fruits and vegetables by breaking or/weakening the cell walls, and therefore, modifying the release of biocompounds during digestion.

Cells exhibited shrinkage after convective drying, as can be observed in Fig. 1 $b_{1}$, resulting in a disruption of the cellular structure. Several authors ${ }^{13,17}$ have agreed that during convective drying, one of the most important phenomena is cell shrinkage, which leads to a major modification of the product structure and allows the release of water. Smith et al. ${ }^{35}$ observed that convective drying caused cell rupture and dislocation resulting in a denser food porosity. This can be seen in Fig. $1 b_{2}$, after in vitro gastric digestion, where the open pores on the surface of the structure have been eliminated and many of the interior cell walls ruptured. Fig. 1 $\mathrm{c}_{1}$ shows the microstructure of the FD sample before in vitro digestion. A certain disruption and shrinkage of the cell structure was observed, although to a lesser extent than in convective drying. This effect was also observed in freeze-dried Red Fuji apple by Huang et al. $^{36}$ and in freeze-dried Idared apple by Lewicki and Pawlak. ${ }^{37}$ Also, Smith et al. ${ }^{35}$ observed that freeze-dried carrots shrank very little but had visible surface cracks and loss of color. An increase in the destruction of cell-wall material can be observed as a result of the in vitro gastric digestion process (Fig. 1 $\mathrm{c}_{2}$ ). Changes resulted in an almost complete elimination of the initial porous structure seen in undigested raw beetroot. A similar result was observed by Dalmau et $a l^{38}$ in freeze-dried Granny Smith apples after $180 \mathrm{~min}$ of in vitro gastric digestion, when changes during digestion eliminated most of the pore structure observed in undigested raw apple.

Overall, microstructural changes were observed as a result of both drying and in vitro gastric digestion compared to the undigested raw beetroot microstructure. Compared to raw beetroot, $\mathrm{CD}$ beetroot exhibited the greatest changes, both before and after digestion.

3.1.2. Image analysis. Using the previously described method, the scanning electron microscope photographs were analyzed and the cell number per unit of tissue surface and the cell area percentile profiles of untreated and dried beetroot samples before (raw, $\mathrm{CD}$ and FD samples) and after in vitro gastric digestion (raw180, CD180 and FD180) were estimated. Results are presented in Table 1 (cell number per unit of
Table 1 Cell number per unit of tissue surface of raw and dried (CD and FD) beetroot before and after $180 \mathrm{~min}$ of in vitro gastric digestion. Significant differences $(p<0.05)$ before and after in vitro digestion are indicated by different lowercase letters, among raw and processed samples by different capital letters and among digested samples by numbers (Tukey's test, $p<0.05$ )

\begin{tabular}{ll}
\hline Sample & Cell number $/ \mathrm{mm}^{2}$ \\
\hline Raw & $289 \pm 4 \mathrm{aC}$ \\
Raw180 & $171 \pm 5 \mathrm{~b} 2$ \\
CD & $425 \pm 1 \mathrm{aB}$ \\
CD180 & $250 \pm 18 \mathrm{~b} 1$ \\
FD & $370 \pm 40 \mathrm{aA}$ \\
FD180 & $190 \pm 20 \mathrm{~b} 2$
\end{tabular}

tissue surface) and Fig. 2 (cell area percentile profiles). In Fig. 2, the percentiles represent the percentages of cells whose areas are equal or smaller to the value obtained; thus, they can help to evaluate changes in the microstructure, reflecting and quantifying the cell size change observed in SEMimages.

As can be seen in Table 1, dried samples (CD and FD) before digestion exhibited significantly higher cell numbers per area unit $(p<0.05)$ than raw beetroot, the CD sample being the one with the highest cell number $(p<0.05)(47 \pm 2 \%$ higher than in raw sample). As can be seen in Fig. 2, different percentile profiles were obtained for each sample. The percentage of larger areas was higher $(p<0.05)$ in the raw sample than in CD and FD samples; for example, $80 \%$ of areas were smaller than $0.067 \mathrm{~mm}^{2}$ in the raw sample but smaller than $0.016 \mathrm{~mm}^{2}$ and $0.025 \mathrm{~mm}^{2}$ in $\mathrm{CD}$ and FD samples, respectively. Therefore, $80 \%$ of cells were approximately $76 \%$ and $63 \%$ smaller $(p<0.05)$ when samples were dried by convective drying or freeze-drying, respectively. Although both CD and FD samples exhibited important cell shrinkage, this effect was greater when beetroot was dried convectively. From these results it can be concluded that drying caused a collapse of the cell walls causing volume shrinkage, which resulted in bigger cell numbers per area unit and smaller sizes according to the percentile profiles. ${ }^{39,40}$

All samples after gastric in vitro digestion presented significantly ( $p<0.05$ ) lower cell numbers per area unit $(41-49 \%$ less) than samples before in vitro digestion (Table 1). Ramírez et $a .^{41}$ also observed reductions of cell numbers per area unit between 34 and $66 \%$ after different treatments, which can affect the original microstructure, such as immersion in boiling water, vacuum impregnation, freezing/thawing and compression. Also, significantly $(p<0.05)$ larger cell sizes were measured after in vitro gastric digestion; for example, $80 \%$ of areas were smaller $(p<0.05)$ than $0.067 \mathrm{~mm}^{2}$ and $0.310 \mathrm{~mm}^{2}$ in raw samples before and after $180 \mathrm{~min}$ of gastric in vitro digestion, respectively; smaller $(p<0.05)$ than $0.016 \mathrm{~mm}^{2}$ and $0.116 \mathrm{~mm}^{2}$ in CD samples before and after $180 \mathrm{~min}$ of gastric in vitro digestion, respectively; and smaller $(p<0.05)$ than $0.025 \mathrm{~mm}^{2}$ and $0.130 \mathrm{~mm}^{2}$ in FD samples before and after $180 \mathrm{~min}$ of gastric in vitro digestion, respectively. However, the integrity of the dried samples was higher exhibiting smaller sizes. 


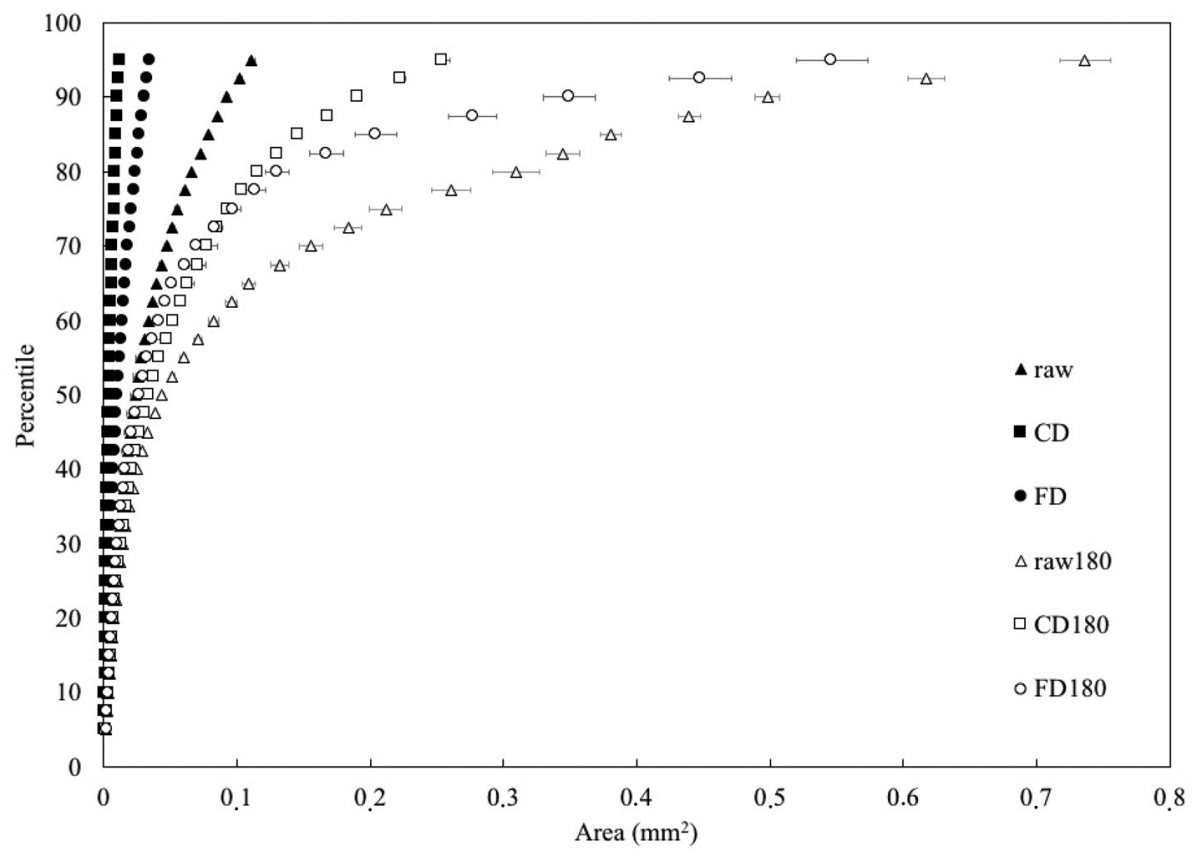

Fig. 2 Cell area percentile profiles of raw, convectively dried and freeze-dried samples before and after 180 min of gastric in vitro digestion.

Therefore, in vitro gastric digestion caused considerable disruption of the cell wall structure, which resulted in a notable decrease of the cell number per area unit and, at the same time, relevant increase of the measured areas, which could be attributed not only to hydration and swelling of cells but also to the holes left by several broken cells or cell walls.

3.1.3. Moisture content and acidity. Table 2 shows the changes in moisture and acidity contents of raw and dried beetroot during in vitro gastric digestion. The initial moisture content $(6.67 \pm 0.04 \mathrm{~g}$ water per $\mathrm{g} \mathrm{dm})$ of raw beetroot was similar to the previously reported value for beetroot by $\mathrm{Ng}$ et $a l .{ }^{42}$ No significant differences $(p<0.05)$ were observed among the initial moisture content of raw and dried samples.

The moisture content increased significantly $(p<0.05)$ in all samples after $180 \mathrm{~min}$ in vitro gastric digestion by about 73,153 , and $79 \% \mathrm{dm}$ in raw, $\mathrm{CD}$ and FD samples, respectively. However, the most important change in moisture took place during the first $45 \mathrm{~min}$ of digestion (48, 119 and $41 \% \mathrm{dm}$ significant increase ( $p<0.05$ ) for raw, CD and FD samples, respectively). The CD sample exhibited the highest capacity $(p<0.05)$ to absorb water $(153 \% \mathrm{dm})$ after $180 \mathrm{~min}$ of digestion. The equilibrium moisture content, measured after $24 \mathrm{~h}$ of in vitro gastric digestion, corresponded to significant moisture increases $(p<0.05)$ of $107 \%$

Table 2 Changes in moisture and acidity content of raw and dried beetroots during in vitro digestion. 9 replicates for each sample were done. The results are expressed as value \pm standard deviation

\begin{tabular}{|c|c|c|c|c|c|c|}
\hline 0 & $6.67 \pm 0.04 \mathrm{Aa}$ & $6.64 \pm 0.02 \mathrm{Aa}$ & $6.60 \pm 0.03 \mathrm{Aa}$ & $0.79 \pm 0.02 \mathrm{Aa}$ & $0.85 \pm 0.01 \mathrm{Ba}$ & $0.77 \pm 0.03 \mathrm{Aa}$ \\
\hline 0.5 & $7.16 \pm 0.01 b$ & $8.65 \pm 0.02 b$ & $6.78 \pm 0.02 b$ & $0.76 \pm 0.01 b$ & $1.02 \pm 0.05 b$ & $0.89 \pm 0.02 b$ \\
\hline 10 & $8.28 \pm 0.02 c$ & $10.39 \pm 0.03 c$ & $6.93 \pm 0.03 c$ & $0.82 \pm 0.02 \mathrm{c}$ & $0.98 \pm 0.20 b$ & $1.00 \pm 0.03 c$ \\
\hline 45 & $9.32 \pm 0.04 f$ & $13.70 \pm 0.02 \mathrm{f}$ & $8.42 \pm 0.02 f$ & $1.22 \pm 0.01 \mathrm{f}$ & $1.67 \pm 0.15 \mathrm{e}$ & $1.22 \pm 0.06 \mathrm{e}$ \\
\hline 60 & $9.89 \pm 0.04 \mathrm{~g}$ & $14.60 \pm 0.01 \mathrm{~g}$ & $9.31 \pm 0.02 \mathrm{~g}$ & $1.43 \pm 0.01 \mathrm{~g}$ & $1.81 \pm 0.14 f$ & $1.26 \pm 0.02 \mathrm{f}$ \\
\hline 90 & $10.62 \pm 0.01 \mathrm{~h}$ & $16.14 \pm 0.02 \mathrm{~h}$ & $10.23 \pm 0.01 \mathrm{~h}$ & $1.40 \pm 0.01 \mathrm{~g}$ & $1.83 \pm 0.01 \mathrm{f}$ & $1.29 \pm 0.04 \mathrm{~g}$ \\
\hline 120 & $10.80 \pm 0.02 \mathrm{i}$ & $16.46 \pm 0.02 \mathrm{i}$ & $10.52 \pm 0.03 \mathrm{i}$ & $1.45 \pm 0.02 \mathrm{~g}$ & $1.83 \pm 0.03 \mathrm{f}$ & $1.34 \pm 0.06 \mathrm{~h}$ \\
\hline 180 & $11.61 \pm 0.03 \mathrm{j}$ & $16.82 \pm 0.01 \mathrm{j}$ & $11.87 \pm 0.01 \mathrm{j}$ & $1.44 \pm 0.02 \mathrm{~g}$ & $1.82 \pm 0.05 f$ & $1.42 \pm 0.04 \mathrm{i}$ \\
\hline Ceq. & $13.82 \pm 0.02 \mathrm{k}$ & $18.12 \pm 0.02 \mathrm{k}$ & $14.96 \pm 0.02 \mathrm{k}$ & $1.43 \pm 0.11 \mathrm{~g}$ & $1.80 \pm 0.06 \mathrm{f}$ & $1.58 \pm 0.09 \mathrm{j}$ \\
\hline
\end{tabular}

Different lowercase letters for the same parameter and same sample indicates significant differences in time. Different capital letters for the same parameter indicate significant differences between initial samples. 
$\mathrm{dm}_{\mathrm{o}}, 153 \% \mathrm{dm}_{\mathrm{o}}$ and $109 \% \mathrm{dm}$ for raw, CD and FD samples, respectively. This could be due to the damage of the cellular structure caused by drying, which facilitated water transport within the food matrix. ${ }^{43}$ Previous in vitro and in vivo studies have also reported increases in food moisture content during gastric digestion. For example, Bornhorst et al. ${ }^{44}$ observed moisture content increases of 75 and $23 \% \mathrm{dm}$ in white and brown rice after

$180 \mathrm{~min}$ of in vivo digestion in pigs, and Bornhorst et al. $^{45}$ observed moisture content increases of 79 and $95 \% \mathrm{dm}$ in raw and roasted almonds after $120 \mathrm{~min}$ of in vitro digestion. Dalmau et $a l^{38}$ reported that the moisture content increased after $180 \mathrm{~min}$ of in vitro digestion in raw, freeze-dried and convective-dried Granny Smith apples by $6 \pm 1,8 \pm 1$ and $11 \pm 2 \% \mathrm{dm}_{\mathrm{o}}$, respectively, the convectively dried sample being the one with the highest water content.

The initial acidity of raw beetroot $(0.79 \pm 0.02 \mathrm{~g}$ per $100 \mathrm{~g} \mathrm{dm}_{\mathrm{o}}$ ) was within the range $(0.7-0.9 \mathrm{~g}$ malic acid per $100 \mathrm{~g} \mathrm{dm}_{\mathrm{o}}$ ) previously reported by Chandra et al. ${ }^{46}$ No significant differences were observed between the acidity of the raw and dried samples. The acidity of all samples significantly increased during in vitro digestion, the highest increases taking place during the first $60 \min (82 \pm 1,113 \pm 1$ and $57 \pm$ $1 \% \mathrm{dm}_{\mathrm{o}}$, in raw, $\mathrm{CD}$ and FD samples, respectively). After $180 \mathrm{~min}$ of digestion, the acidity gains were of $83 \pm 1,114 \pm 1$ and $78 \pm 1 \% \mathrm{dm}_{\mathrm{o}}$, in raw, CD and FD samples, respectively.

CD samples exhibited acidity gains significantly $(p<0.05)$ higher during digestion than the raw sample. The microstructural changes during drying and digestion promoted the damage of cell walls resulting in different rates of acid uptake. The equilibrium acid content in CD and FD samples (1.80 and $1.58 \mathrm{~g}$ per $100 \mathrm{~g} \mathrm{dm}$, respectively) was significantly higher ( $p<$ $0.05)$ than that of the raw sample ( $1.43 \mathrm{~g}$ per $\left.100 \mathrm{~g} \mathrm{dm}_{\mathrm{o}}\right)$. The results obtained in this study are the opposite to those obtained by Dalmau et al., ${ }^{38}$ where they observed that raw, CD and FD acidity of Granny Smith apples significantly decreased during in vitro digestion. The decreases in acidity during digestion observed in this previous study were hypothesized to be caused by the higher acidity of raw apples before digestion $(5.1 \pm 0.2 \mathrm{~g}$ per $100 \mathrm{~g}$ malic acid), which might be higher than the acidity of the gastric juice. However, the acidity of raw beetroot before digestion was $0.79 \pm 0.02 \mathrm{~g}$ per $100 \mathrm{~g}$ dmo malic acid, which was significantly lower than the acidity of the gastric juice, resulting in acid uptake by beetroot when immersed in gastric juice. Similarly, Mennah-Govela et al. ${ }^{47}$ observed acidity increases in sweet potatoes, during in vitro gastric digestion.

\subsection{Release of bioactive compounds}

Table 3 shows the TPC and AA (measured using the ABTS, CUPRAC and FRAP methods) of raw and dried samples. The same initial TPC in raw samples $(4.2 \pm 0.2 \mathrm{mg}$ GAE per $\mathrm{g} \mathrm{dm})$ was previously reported for Beta vulgaris beetroot by Kujala et $a l^{48}$

Beetroot samples after processing (drying followed by rehydration, $\mathrm{CD}$ and $\mathrm{FD}$ samples) exhibited significant changes $(p<0.05)$ in their bioactive compound content. When comparing the results for the dried samples (CD and FD) to those for the raw one, it can be seen that processing promoted higher $(p<0.05)$ TPC losses in the FD sample (74\%) than in the $\mathrm{CD}$ sample $(41 \%)$. Guiné et al. $^{49}$ reported no significant TPC changes due to convective drying and freezedrying of cucumber, concluding that these processes do not affect the TPC. In other cases, the TPC of the samples decreased due to drying, exhibiting similar behavior to that observed in this study. Vega-Gálvez et $a l^{50}$ and Ferreira et al. ${ }^{51}$ reported TPC decreases of $74 \%$ and $68 \%$ after convec-

tive drying $\left(60^{\circ} \mathrm{C}\right.$ and $\left.2 \mathrm{~m} \mathrm{~s}^{-1}\right)$ of red pepper and sun-drying of pear, respectively, compared to raw samples. Asami et al. ${ }^{52}$ reported TPC decreases of $33 \%$ in strawberries after freezedrying.

Three methods were used to evaluate the antioxidant activity (AA) of both the beetroot samples and the gastric juice: ABTS, CUPRAC and FRAP analyses. Due to the fact that each method is based on a different chemical system and/or reaction, different results of AA could be expected, depending on the method used for analysis. The selection of different methods allows a better understanding of the wide variety and range of action of antioxidant compounds present in beetroot. $^{53}$ The average values for the AA of raw beetroot were $12.4 \pm 0.9,25.5 \pm 0.9$ and $12.1 \pm 0.8 \mathrm{mg}$ Trolox per $\mathrm{g} \mathrm{dmo}$ as measured by the ABTS, CUPRAC and FRAP methods, respect-

Table 3 TPC and AA (measured using the ABTS, CUPRAC and FRAP methods) of raw and dried samples. 9 replicates for each sample were done. The results are expressed as value \pm standard deviation

\begin{tabular}{|c|c|c|c|c|c|}
\hline & & TPC (mg GAE per $\mathrm{g} \mathrm{dm}_{\mathrm{o}}$ ) & \multicolumn{3}{|c|}{ Antioxidant activity (mg Trolox per $\mathrm{g} \mathrm{dm}$ ) } \\
\hline \multirow[t]{2}{*}{$C_{\mathrm{o}}$ Beetroot cubes } & Raw & $4.2 \pm 0.2 \mathrm{a}$ & $12.4 \pm 0.9 \mathrm{a}$ & $25.4 \pm 0.9 \mathrm{a}$ & $12.1 \pm 0.8 \mathrm{a}$ \\
\hline & FD & $1.1 \pm 0.2 \mathrm{c}$ & $8.3 \pm 0.7 \mathrm{c}$ & $9.1 \pm 0.8 \mathrm{~b}$ & $5.8 \pm 0.4 b$ \\
\hline \multirow[t]{2}{*}{$C_{\text {eq. }}$. Beetroot cubes } & Raw & $2.20 \pm 0.02 \mathrm{a}$ & $4.46 \pm 0.18 \mathrm{a}$ & $4.24 \pm 0.18 \mathrm{a}$ & $5.3 \pm 0.2 \mathrm{a}$ \\
\hline & $\mathrm{CD}$ & $0.77 \pm 0.03 \mathrm{~b}$ & $0.12 \pm 0.02 \mathrm{c}$ & $0.09 \pm 0.02 b$ & $0.84 \pm 0.07 \mathrm{~b}$ \\
\hline & $\mathrm{CD}$ & $5.28 \pm 0.02 \mathrm{~b}$ & $17.83 \pm 0.08 b$ & $35.77 \pm 0.06 \mathrm{~b}$ & $30.21 \pm 0.08 \mathrm{~b}$ \\
\hline & FD & $2.25 \pm 0.02 \mathrm{c}$ & $13.46 \pm 0.11 \mathrm{c}$ & $16.07 \pm 0.06 \mathrm{c}$ & $25.63 \pm 0.06 \mathrm{c}$ \\
\hline
\end{tabular}

Different lowercase letters for the same parameter indicates significant differences between samples. 
ively. The same initial values of ABTS and FRAP in raw samples was previously reported for Beta vulgaris beetroot by Sawicki et al. ${ }^{54}$ and Raikos et al., ${ }^{55}$ respectively.

After processing, the AA decreased more $(p<0.05)$ in the CD sample (49\%) than in the FD sample (33\%) according to the ABTS method, and by approximately the same according to CUPRAC (62-64\% decrease) and FRAP (52\% decrease) methods. Loncaric et al..$^{56}$ measured an AA decrease (ABTS method) in freeze-dried Fuji apples of ca. 64\%.

In order to evaluate the release of bioactive compounds during the in vitro gastric digestion of beetroot samples (raw, CD and FD samples), the total polyphenol content (TPC) and the antioxidant activity (AA) were measured at different times during the experiments in both the food and gastric juice.

Fig. 3 shows the release of TPC (Fig. 3a) and AA (measured using the ABTS method in Fig. 3b, CUPRAC method in Fig. 3c, and FRAP method in Fig. 3d) of raw and dried beetroot matrix during $180 \mathrm{~min}$ of in vitro gastric digestion. The equilibrium values (after $24 \mathrm{~h}$ of in vitro gastric digestion) used to estimate the release according to eqn (1) are shown in Table 3 . It can be seen that both TPC and AA initial (before digestion) were lower in processed samples than raw samples.
The TPC releases from the raw, CD and FD samples (after $180 \mathrm{~min}$ of in vitro gastric digestion) were $1.9 \pm 0.1,1.6 \pm 0.1$ and $0.6 \pm 0.1 \mathrm{mg}$ gallic acid per $\mathrm{g} \mathrm{dm_{o }}$, respectively. Also, the AA measured using the CUPRAC method was decreased ( $p<$ 0.05 ) by $14.6 \pm 0.6 \mathrm{mg}$ Trolox per $\mathrm{g} \mathrm{dm}$ in the raw sample, but by $6.8 \pm 0.4$ and $6.0 \pm 0.4 \mathrm{mg}$ Trolox per $\mathrm{g} \mathrm{dm}_{\mathrm{o}}$ in $\mathrm{CD}$ and FD samples, respectively. However, when the AA was measured using the ABTS and FRAP methods, decreases $(p<0.05)$ were less different. These results indicate that although the biocompound contents were significantly $(p<0.05)$ lower in processed samples, the total quantity released from these samples was comparable, probably due to the damaged microstructure which eased the mass transfer between the solid and the gastric juice.

Dried beetroot exhibited higher release $(p<0.05)$ of TPC $(64.1 \pm 0.6$ and $53.6 \pm 0.9 \%$ in $\mathrm{CD}$ and FD samples, respectively) than in the raw sample $(46.6 \pm 0.2 \%)$ after $180 \mathrm{~min}$ of in vitro gastric digestion. Similar decreases in TPC (of 44.6\%) were reported by Bouayed et $a l^{57}$ in Jonaprinz apples during $60 \mathrm{~min}$ of in vitro gastric digestion. Kamiloglu et $a l^{58}$ observed a $65 \%$ decrease in the TPC of black carrots after $120 \mathrm{~min}$ of in vitro gastric digestion. Chen et al. ${ }^{59}$ observed that TPC significantly decreased in 25 of the 33 studied fruits $(8-73 \%)$ and
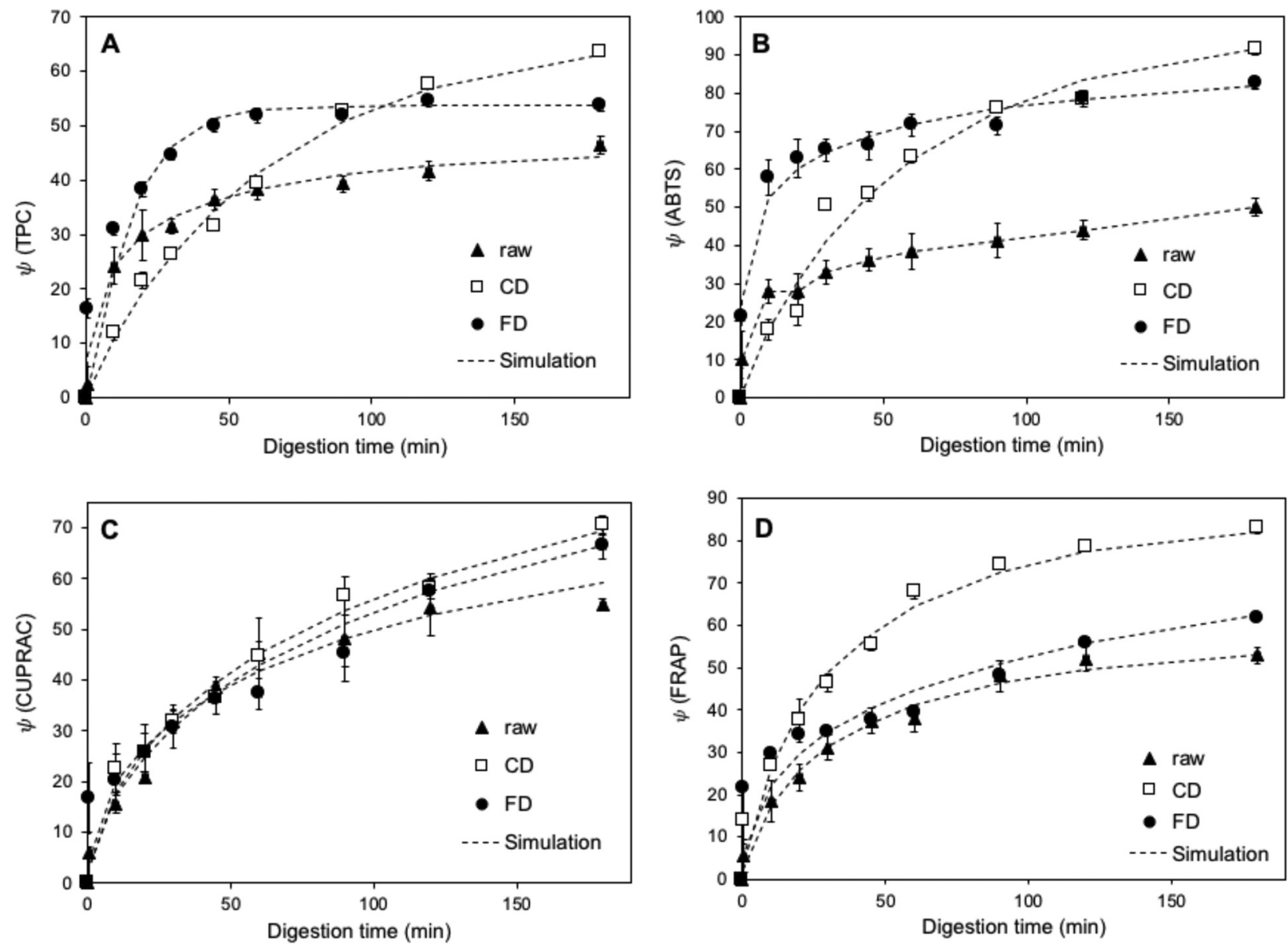

Fig. 3 Release of TPC (A) and AA (B: ABTS, C: CUPRAC and D: FRAP) from the raw and dried beetroot samples during in vitro digestion. 
increased in the remaining eight, during the gastric stage of in vitro digestion. These results indicate that not only the initial TPC value, but also the structure of the food matrix, may be important in the release of nutrients from food matrices during digestion.

Although raw beetroot exhibited the highest AA figure before digestion, this sample had the smallest release $(p<$ $0.05)(53 \pm 1 \%$ as the average of the three ABTS, CUPRAC and FRAP methods) after $180 \mathrm{~min}$ of in vitro gastric digestion. The AA releases in dried samples after $180 \mathrm{~min}$ of digestion were higher $(p<0.05)(82 \%$ in the $\mathrm{CD}$ sample and $76 \%$ in $\mathrm{FD}$ samples, as averages). Thus, both drying treatments altered the cellular structure resulting in samples with higher release.

The total polyphenol content (TPC) and antioxidant activity (ABTS, CUPRAC, and FRAP methods) were also measured in the gastric juice at different times, including $24 \mathrm{~h}$ to estimate the equilibrium figure, during the in vitro gastric digestion of raw and dried samples.

To facilitate the interpretation of the results, the TPC and AA figures measured in the gastric juice, including the equilibrium figures measured after $24 \mathrm{~h}$ of in vitro gastric digestion,

were expressed in $\mathrm{mg} \mathrm{g}^{-1} \mathrm{dm}$ taking into account the mass of sample/volume of gastric juice ratio used in the experiments and the moisture content of beetroot samples at each time during the in vitro gastric digestion experiments. The equilibrium TPC and AA figures, expressed using this methodology, are also shown in Table 3.

It can be seen in Table 3 that the equilibrium TPC and AA were significantly higher than the expected values, taking into account the initial figures in the solid matrix. After $24 \mathrm{~h}$ of in vitro gastric digestion, the TPC in the gastric juice was $25 \%$, $114 \%$ and $104 \%$ higher $(p<0.05)$ than the initial concentration in raw, CD and FD beetroot, respectively. Similarly, the $\mathrm{AA}$ in the gastric juice increased more than was expected, the equilibrium AA being 61-182\% (ABTS method), 76-270\% (CUPRAC method) and 262-420\% (FRAP method) higher than the initial AA in beetroot samples. It is worth mentioning that the highest increases were observed in CD samples. These TPC and AA increases in gastric juice after in vitro digestion could be due to the degradation of molecules with no original antioxidant activity, present in the food matrix, to smaller molecules with antioxidant activity; it may also be that there are molecules with initial antioxidant activity but then they degrade and lose that activity. However, the balance between the two effects is positive and there is a release greater than $100 \%$. Wootton-Beard et $a .^{60}$ pointed out that the $\mathrm{pH}$ of a substance is known to affect the racemisation of molecules, possibly creating two chiral enantiomers with different biological reactivities. In the literature, there is also the suggestion that depending on the structural changes which occur, the resulting metabolites may react differently across different assays. Fazzari et al. ${ }^{61}$ indicated that moderate increase in the total phenolics and a slight increase in anthocyanins for frozen sweet cherries following pepsin digestion were possible because pepsin digestion released phenolic compounds from the cherry fruit matrix. Additionally, further increases in anti- oxidant activity could be caused by the acid $\mathrm{pH}$ of digestion $(\sim 2)$, which favors the formation of some anthocyanin derivatives. Similar increases in anthocyanins following pepsin

digestion have been observed for pomegranate juice. ${ }^{62}$ Furthermore, Rodríguez-Roque et al. ${ }^{63}$ indicated that the low $\mathrm{pH}$ and the enzyme action of gastric digestion could hydrolyze phenolic compounds bound to proteins and carbohydrates from orange, kiwi and pineapple juice, increasing the concentration of phenolic compounds after digestion. There is also the suggestion that depending on the structural changes which occur during digestion, the resulting metabolites may react differently across different assays. The release of certain antioxidant components from food constituents with no original antioxidant activity such as amino acids, sugars and uronic acids may increase the values of certain total antioxidant capacity assays, leading to overestimated results if the antioxidant activity of a specific compound is compared before and after digestion. ${ }^{64}$ Also, it has been previously reported that polyphenols and other food constituents such as glucids, amino acids and proteins in aqueous solutions may produce a positive result in ORAC and TEAC antioxidant capacity assays. ${ }^{65}$

In order to estimate the release of the biocompounds in the gastric juice according to eqn (2), the maximum concentration was considered to be equal to the initial concentration in the beetroot sample before digestion (Table 3). Results of release in gastric juice are shown in Fig. 4 (for TPC in Fig. 4a; for AA according to ABTS, CUPRAC and FRAP methods in Fig. 4b, c and $\mathrm{d}$, respectively).

It can be seen in Fig. 4 that the TPC and AA release measured in the gastric juice after $180 \mathrm{~min}$ of in vitro gastric digestion was higher than $100 \%$ in all cases. TPC release increased $(p<0.05)$ by $132 \%, 188 \%$ and $140 \%$ in raw, CD and FD samples, respectively, in comparison with the maximum estimated quantity (initial TPC in beetroot samples before digestion). These increments were even higher $(p<0.05)$ in the AA release (154-279\% according to the ABTS method; 168$331 \%$ according to the CUPRAC method; and 369-537\% according to the FRAP method). When comparing among beetroot samples, it can be observed that the CD sample exhibited the highest release in all cases.

These trends may indicate that drying treatments altered the cellular structure such that the dried beetroot released a higher amount of polyphenols and antioxidant compounds and provoked the degradation of molecules with no original antioxidant activity to smaller molecules with antioxidant activity during in vitro gastric digestion.

\subsection{Mass transfer kinetics}

The Weibull model was used to mathematically describe the release kinetics for both the release of the total polyphenol contents and the antioxidant activity from the beetroot matrix and their uptake by gastric juice during in vitro digestion. Using the experimental results obtained at different digestion times, the $\alpha$ and $\beta$ parameters of the Weibull model were identified for each measured quantity in each sample, and the 

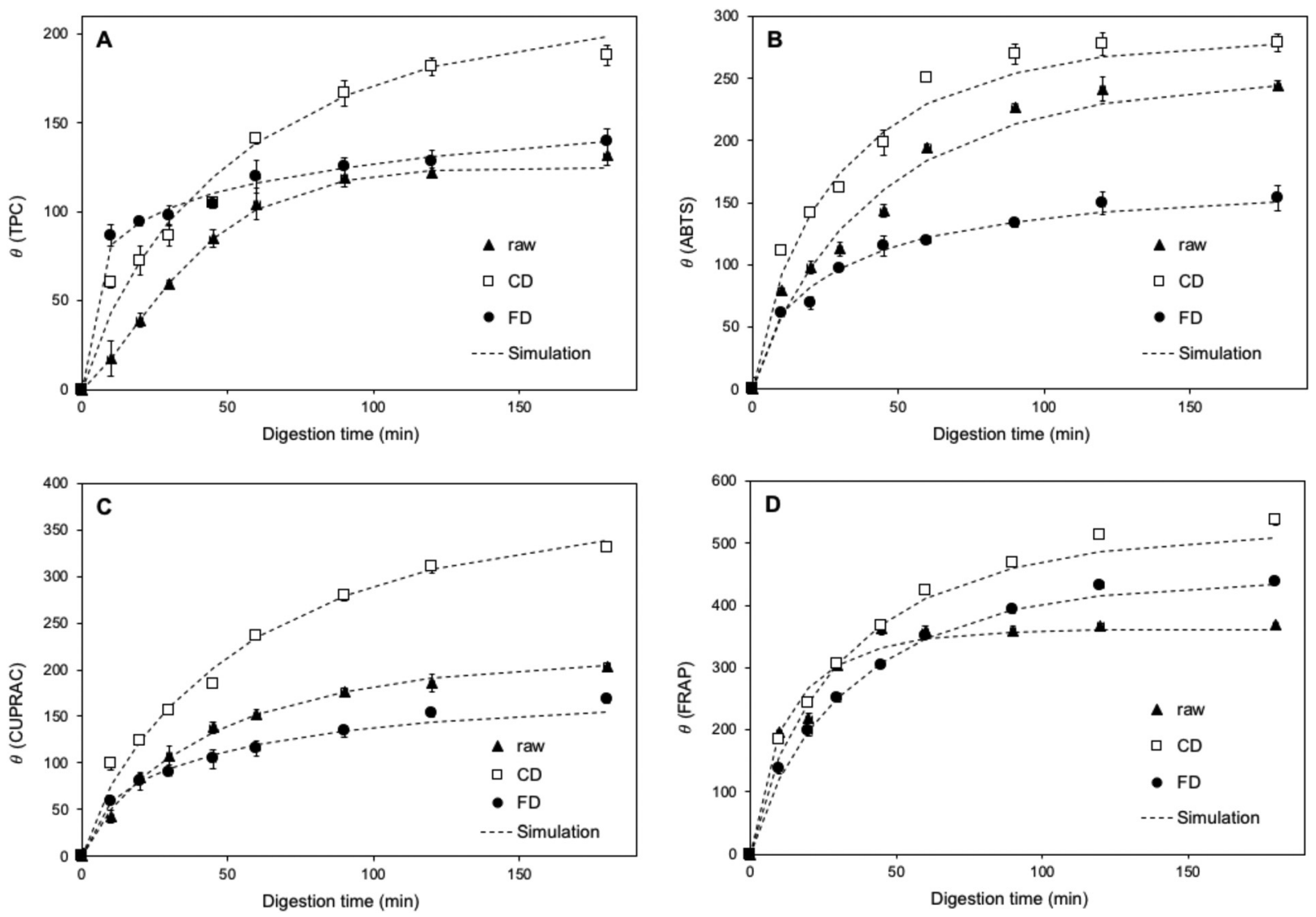

Fig. 4 Release of TPC (A) and AA (B: ABTS, C: CUPRAC, and D: FRAP) in the gastric juice from the raw and dried beetroot samples during in vitro digestion.

Table 4 Release of the TPC (A) and AA (B: ABTS, C: CUPRAC and D: FRAP) from raw and dried beetroot samples during in vitro digestion. Equilibrium values, identified parameters of the Weibull model and confidence interval $(\mathrm{Cl})$ and standard error $(\mathrm{SE})$ associated with each parameter

\begin{tabular}{|c|c|c|c|c|c|c|c|c|c|}
\hline & & $\Psi_{\text {eq. }}$ & $\alpha \times 10^{-3}(\mathrm{~s})$ & $\mathrm{CI}(\mathrm{s})$ & SE & $\beta$ & $\mathrm{CI}$ & SE & MRE \\
\hline & $\mathrm{CD}$ & $68.1 \pm 0.3$ & 3.889 & {$[3.538,4.239]$} & 0.152 & 0.942 & {$[0.817,1.068]$} & 0.054 & 2.2 \\
\hline & FD & $53.6 \pm 0.8$ & 0.990 & {$[0.974,2.724]$} & 0.379 & 1.137 & {$[0.218,0.508]$} & 0.063 & 5.9 \\
\hline & $\mathrm{CD}$ & $98.0 \pm 0.1$ & 3.538 & {$[2.835,4.242]$} & 0.305 & 0.904 & {$[0.642,1.165]$} & 0.113 & 7.0 \\
\hline & FD & $95.1 \pm 0.3$ & 1.208 & {$[0.890,1.527]$} & 0.138 & 0.313 & {$[0.254,0.372]$} & 0.025 & 5.6 \\
\hline AA (CUPRAC) & Raw & $83.4 \pm 1.8$ & 7.221 & {$[5.620,8.894]$} & 0.710 & 0.524 & {$[0.438,0.684]$} & 0.053 & 3.9 \\
\hline \multirow[t]{3}{*}{ AA (FRAP) } & Raw & $56 \pm 2$ & 2.406 & {$[2.090,2.722]$} & 0.137 & 0.708 & {$[0.587,0.829]$} & 0.053 & 2.0 \\
\hline & $\mathrm{CD}$ & $85.6 \pm 0.7$ & 2.277 & {$[1.867,2.687]$} & 0.178 & 0.740 & {$[0.562,0.918]$} & 0.077 & 5.2 \\
\hline & FD & $93.7 \pm 0.2$ & 8.902 & {$[3.801,27.57]$} & 5.154 & 0.482 & {$[0.179,0.410]$} & 0.050 & 6.0 \\
\hline
\end{tabular}

corresponding confidence intervals and the standard error associated with the parameters were estimated. Also, the mean

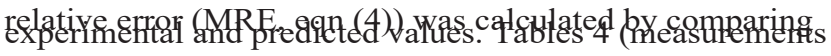

carried out on the food matrix) and 5 (measurements carried out on the gastric juice) show these results. The simulated curves using the Weibull model are also represented together with the experimental values for all samples in Fig. 3 and 4 by dashed lines. The release in beetroot cubes and in gastric juice (eqn (5) and (6), respectively) is calculated taking into account the definitions described in eqn (3) and (4), together with the Weibull model (eqn (3)).

$$
\begin{aligned}
& \Psi_{\text {calc } 1 / 41-} C_{\text {eq: }} \times e^{\left.-{ }^{t}\right)_{\alpha} \mathbf{i}} \\
& \theta_{\text {calc } 1 / 4} 1-1-C_{C}^{C_{\text {eq: }}} \times e^{-{ }^{\left.t{ }_{\bar{\alpha}}\right)_{\beta} \mathbf{i}}}
\end{aligned}
$$

The obtained MREs (Tables 4 and 5) were similar to or lower than $8.5 \%$ in most of the cases. From these results 
Table 5 Uptake of TPC (A) and AA (B: ABTS, C: CUPRAC, and D: FRAP) in the gastric juice during in vitro digestion. Equilibrium values, identified parameters of the Weibull model and corresponding confidence interval $(\mathrm{Cl})$ and standard error $(\mathrm{SE})$ associated with each parameter

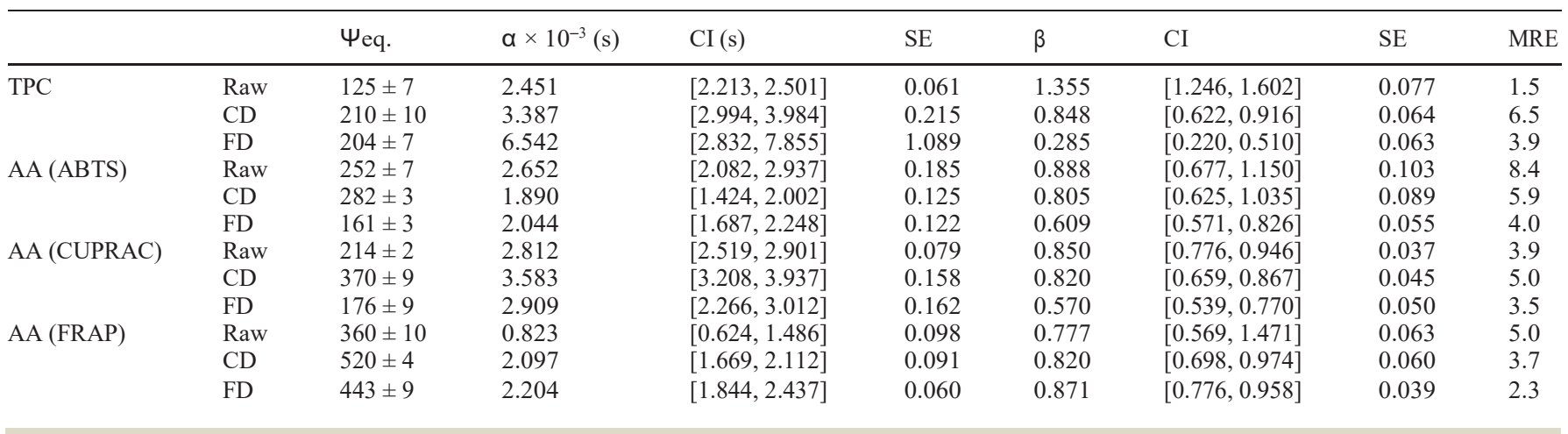

(Tables 4 and 5), and the comparison with the experimental results shown in Fig. 2 and 3, it can be concluded that the proposed model successfully simulated the release kinetics of the different measured quantities in raw and drying beetroots during in vitro gastric digestion. Dalmau et al. ${ }^{38}$ also simulated satisfactorily the mass transfer kinetics of the different compounds using the Weibull model in raw and processed apples during in vitro gastric digestion.

It can be seen in Table 4 that the $\alpha$ parameter for TPC release increased $219 \%$ in CD samples and decreased $18.5 \%$ in FD samples compared to the value for the raw sample. This indicates a decrease in the rate of change of TPC of CD samples, and a slight increase in the FD sample. The $\beta$ parameter for TPC loss kinetics was 0.465 in the raw sample but close to 1 in CD and FD samples. This indicates that, in dried samples, the kinetic was close to a first-order kinetic with a constant input rate. ${ }^{20}$

Regarding the AA change kinetics measured by the ABTS method, $\alpha$ decreased by 23 and $72 \%$ in CD and FD samples, compared to the raw sample. The $\alpha$ figure for the AA change kinetics measured using CUPRAC and FRAP was similar in both raw and CD samples (only 11\% higher and 5\% lower in the CD sample according to the CUPRAC and FRAP assays, respectively) but was much higher in the FD sample $(26 \%$ and $270 \%$ higher in the FD sample according to CUPRAC and FRAP assays, respectively). The identified $\beta$ parameter for AA change kinetics was lower than 1 in all cases, indicating convexity in the change curves and thus, a decreasing change rate over time. However, the $\beta$ figures showed different trends depending on the method used to measure the AA. It can be seen that the $\beta$ parameter for the $C D$ sample according to all methods was higher than those for the other samples. This may indicate that convective drying eased the release of phenolic compounds during in vitro digestion. These different tendencies may indicate that although graphical trends are similar, their fundamental mechanisms of mass transport may have been modified by the processing method.

With regard to the identified figures for the Weibull model parameters for the kinetics of TPC increases in the gastric juice, $\alpha$ values for the raw and CD samples were similar and significantly lower than those for extraction from the FD samples (increased $167 \%$ in comparison with that for the raw sample), reflecting the slower process of TPC release from the FD sample to the gastric juice. As can be seen in Fig. 4, most of the TPC release from the FD sample took place during the first $10 \mathrm{~min}$ of the digestion, the release kinetic later on being slower. On the other hand, the $\beta$ parameter was higher than 1 for the extraction rate of TPC for gastric juice from the raw sample but lower than 1 for the rest of the samples. This could be explained by the fact that the original cellular structure of the raw sample prevents the TPC release. Thus, the extent of the effects of the gastric juice components in modifying the structure to facilitate the release increased with time. In dried samples, the TPC extraction rate remained high from the beginning of the gastric digestion probably because the original structure of the food matrix was already altered.

Results of AA in gastric juice during in vitro digestion followed trends similar to those observed for the TPC. The gastric juice from FD sample digestion exhibited the lowest AA, together with those for the CD sample, both with higher $\alpha$ figures and lower equilibrium values (Table 5) than those obtained for the raw sample. On the other hand, the $\beta$ parameter was lower than 1 for the extraction rate of AA for gastric juice for all samples with all assays. The $\beta$ parameters for the raw and CD samples were similar and significantly higher than that for extraction from the FD samples with ABTS and CUPRAC assays (increased $32 \%$ in comparison with that for the raw sample). This could also be explained by the fact that the original cellular structure of the raw sample prevents AA release, and in the same way, the extent of the effects of the gastric juice components in modifying the structure to facilitate the release increased with time.

These results further confirm the above-mentioned finding that drying of beetroot affects the microstructure facilitating the extraction of polyphenols and antioxidant compounds from the beetroot matrix during in vitro gastric digestion.

\section{Conclusions}

Drying modified the microstructure and initial composition of dried beetroot compared to raw beetroot. Microstructural ana- 
lyses indicated significant cellular damage and changes as a result of drying and in vitro gastric digestion. These structural modifications resulted in behavioral changes in beetroot during in vitro gastric digestion. In general, dried beetroot showed faster decreases in titratable acidity while moisture content increases were higher in processed samples, compared to raw beetroot, during in vitro gastric digestion. Although drying promoted decreases in total polyphenol content and antioxidant activity before in vitro gastric digestion, dried beetroot showed higher release and better release of bioactive compounds (TPC and AA). However, the TPC and AA increases in gastric juice were higher than the corresponding decreases in beetroot during in vitro digestion, possibly due to the degradation of molecules with no original antioxidant activity, present in the food matrix, to smaller molecules with antioxidant activity. Moreover, it was observed that the CD sample exhibited both a higher loss of phenolic compounds and a higher gain of these compounds in gastric juice, leading to the conclusion that this drying process favors the release of the phenolic compounds of beetroot more than in the FD samples. Furthermore, the Weibull model allowed the satisfactory description of the mass transfer process occurring during in vitro digestion, of both the antioxidant compounds leaving the beetroot matrix, and the uptake of these compounds by the gastric juice. Weibull model parameters were utilized to compare the rate of release/uptake of antioxidant and phenolic compounds from beetroot, and it was observed that drying increased the release of antioxidant and phenolic compounds during in vitro gastric digestion. Given the limited knowledge that is available on this subject at present, it would be interesting to investigate further to better understand how processing can modify the structural characteristics of the ingested foods to modulate the release of active compounds in food matrices.

\section{Nomenclature}

AA Antioxidant activity ( $\mathrm{mg}$ Trolox per $\mathrm{g} \mathrm{dm}_{\mathrm{o}}$ )

$C_{\text {max }}$ Maximum concentration $\left(\mathrm{g} \mathrm{g}^{-1} \mathrm{dm}_{\mathrm{o}}\right.$ or $\mathrm{g}$ per $100 \mathrm{~g} \mathrm{dm}_{\mathrm{o}}$ )

$C_{\mathrm{o}} \quad$ Initial concentration $\left(\mathrm{g} \mathrm{g}^{-1} \mathrm{dm}_{\mathrm{o}}\right.$ or $\mathrm{g}$ per $\left.100 \mathrm{~g} \mathrm{dm}_{\mathrm{o}}\right)$

$C_{\text {calc }} \quad$ Calculated concentration ( $\mathrm{g} \mathrm{g}^{-1} \mathrm{dm}_{\mathrm{o}}$ or $\mathrm{g}$ per $100 \mathrm{~g} \mathrm{dm}_{\mathrm{o}}$ )

$C_{\mathrm{eq}} \quad$ Equilibrium concentration $\left(\mathrm{g} \mathrm{g}^{-1} \mathrm{dm}_{\mathrm{o}}\right.$ or $\mathrm{g}$ per $\left.100 \mathrm{~g} \mathrm{dm}_{\mathrm{o}}\right)$

$C_{\exp } \quad$ Experimental concentration $\left(\mathrm{g} \mathrm{g}^{-1} \mathrm{dm}_{\mathrm{o}}\right.$ or $\mathrm{g}$ per $100 \mathrm{~g} \mathrm{dm}_{\mathrm{o}}$ )

CD Convective drying

$C_{\mathrm{i}} \quad$ Concentration at time $i\left(\mathrm{~g} \mathrm{~g}^{-1} \mathrm{dm}_{\mathrm{o}}\right.$ or $\mathrm{g}$ per $\left.100 \mathrm{~g} \mathrm{dm}_{\mathrm{o}}\right)$

CI Confidence intervals

$\mathrm{dm} \quad$ Dry matter $(\mathrm{g})$

$\mathrm{dm}_{\mathrm{o}} \quad$ Initial dry matter $(\mathrm{g})$

FD Freeze-drying

GAE Gallic acid equivalent

MRE Mean relative error (\%)

SE Standard error of the estimated parameters

SEM Scanning electron microscopy

TPC Total polyphenol content (mg GAE per $\mathrm{g} \mathrm{dm}_{\mathrm{o}}$ )
Inverse kinetic reaction constant of the Weibull model (s) Shape parameter of the Weibull model

\section{Acknowledgements}

The authors would like to acknowledge the financial support of the National Institute of Research and Agro-Food Technology (INIA), co-financed with the ERDF funds (RTA2015-00060-C04-03), and the Balearic Government for the research fellowship (FPI/1814/2015).

\section{Notes and references}

1 J. Wruss, G. Waldenberger, S. Huemer, P. Uygun, P. Lanzerstorfer, U. Müller, et al. Compositional characteristics of commercial beetroot products and beetroot juice prepared from seven beetroot varieties grown in Upper Austria, J. Food Compos. Anal., 2015, 42, 46-55.

2 T. Clifford, G. Howatson, D. J. West and E. J. Stevenson, The potential benefits of red beetroot supplementation in health and disease, Nutrients, 2015, 7(4), 2801-2822.

3 A. Figiel, Drying kinetics and quality of beetroots dehydrated by combination of convective and vacuum-microwave methods, J. Food Eng., 2010, 98(4), 461-470.

4 K. Kaur and A. K. Singh, Drying kinetics and quality characteristics of beetroot slices under hot air followed by microwave finish drying, Afr. J. Agric. Res., 2014, 9(12), 10361044.

5 S. J. Kowalski and J. M. Łechtańska, Drying of red beetroot after osmotic pretreatment: Kinetics and quality considerations, Chem. Process Eng., 2015, 36(3), 345-354.

6 S. Kamiloglu, C. Grootaert, E. Capanoglu, C. Ozkan, G. Smagghe, K. Raes, et al. Anti-inflammatory potential of black carrot (Daucus carota L.) polyphenols in a co-culture model of intestinal Caco-2 and endothelial EA.hy926 cells, Mol. Nutr. Food Res., 2017, 61(2), 1600455.

7 K. Ruse, T. Rakcejeva, R. Galoburda and L. Dukalska, Anthocyanin content in Latvian cranberries dried in convective and microwave vacuum driers, in Research for Rural Development, 2011, pp. 100-106.

8 S. J. Kowalski and J. Szadzińska, Convective-intermittent drying of cherries preceded by ultrasonic assisted osmotic dehydration, Chem. Eng. Process., 2014, 82, 65-70.

9 C. V. Bezerra, L. H. Meller da Silva, D. F. Corrêa and A. M. C. Rodrigues, A modeling study for moisture diffusivities and moisture transfer coefficients in drying of passion fruit peel, Int. J. Heat Mass Transfer, 2015, 85, 750-755.

10 M. A. García-Alvarado, F. M. Pacheco-Aguirre and I. I. RuizLópez, Analytical solution of simultaneous heat and mass 
transfer equations during food drying, J. Food Eng., 2014, 142, 39-45.

11 S. P. Ishwarya and C. Anandharamakrishnan, Spray-FreezeDrying approach for soluble coffee processing and its effect on quality characteristics, J. Food Eng., 2015, 149, 171-180.

12 J. C. Russ, Image analysis of food microstructure, in Computer Vision Technology in the Food and Beverage Industries, 2012, pp. 233-252.

13 Z. Zhang, X. Wang, Y. Li, Q. Wei, C. Liu, M. Nie, et al. Evaluation of the impact of food matrix change on the in vitro bioaccessibility of carotenoids in pumpkin (Cucurbita moschata) slices during two drying processes, Food Funct., 2017, 8(12), 4693-4702.

14 D. J. Paustenbach, The practice of exposure assessment: a state-of-the-art review, J. Toxicol. Environ. Health, Part B, 2000, 3(3), 179-291.

15 F. J. Barba, L. R. B. Mariutti, N. Bragagnolo,

A. Z. Mercadante, G. V. Barbosa-Cánovas and V. Orlien, Bioaccessibility of bioactive compounds from fruits and vegetables after thermal and nonthermal processing, Trends Food Sci. Technol., 2017, 67, 195-206.

16 M. Zahir, V. Fogliano and E. Capuano, Food matrix and processing modulate in vitro protein digestibility in soybeans, Food Funct., 2018, (9), 6326-6336.

17 Ó. Rodríguez, J. V. Santacatalina, S. Simal, J. V. GarciaPerez, A. Femenia and C. Rosselló, Influence of power ultrasound application on drying kinetics of apple and its antioxidant and microstructural properties, J. Food Eng., 2014, 129, 21-29.

18 G. M. Bornhorst and R. P. Singh, Kinetics of in Vitro Bread Bolus Digestion with Varying Oral and Gastric Digestion Parameters, Food Biophys., 2013, 8(1), 50-59.

19 M. Devaux, P. Robert, J. Melcion and F. Le Deschault de Monredon, Particle size analysis of bulk powders using mathematical morphology, Powder Technol., 1997, 90(2), $141-147$.

20 V. S. Eim, D. Urrea, C. Rosselló, J. V. García-Pérez, A. Femenia and S. Simal, Optimization of the Drying Process of Carrot (Daucus carota v. Nantes) on the Basis of Quality Criteria, Drying Technol., 2013, 31, 951-962.

21 M. R. González-Centeno, F. Comas-Serra, A. Femenia, C. Rosselló and S. Simal, Effect of power ultrasound application on aqueous extraction of phenolic compounds and antioxidant capacity from grape pomace (Vitis vinifera L.): Experimental kinetics and modeling, Ultrason. Sonochem., 2015, 22, 506-514.

22 D. Moreira, B. Gullón, P. Gullón, A. Gomes and F. Tavaria, Bioactive packaging using antioxidant extracts for the prevention of microbial food-spoilage, Food Funct., 2016, 7(7), 3273-3282.

23 A. Sturzoiu, M. Stroescu, A. S. Guzun and T. Dobre, Empirical models applied for kinetics extraction of $\beta$ carotene from Rosa canina, Rev. Chim., 2011, 62, 344-348.

24 D. Baş and İ. H Boyacı, Modeling and optimization I: Usability of response surface methodology, J. Food Eng., 2007, 78, 836-845.
25 C. A. Nayak, K. Suguna, K. Narasimhamurthy and N. K. Rastogi, Effect of gamma irradiation on histological and textural properties of carrot, potato and beetroot, J. Food Eng., 2007, 79(3), 765-770.

26 S. M. Carnachan, T. J. Bootten, S. Mishra, J. a. Monro and I. M. Sims, Effects of simulated digestion in vitro on cell wall polysaccharides from kiwifruit (Actinidia spp.), Food Chem., 2012, 133(1), 132-139.

27 H. Palafox-Carlos, J. F. Ayala-Zavala and G. A. GonzálezAguilar, The role of dietary fiber in the bioaccessibility and bioavailability of fruit and vegetable antioxidants, J. Food Sci., 2011, 76(1), R6-15.

28 S. Van Buggenhout, M. Alminger, L. Lemmens, I. Colle, G. Knockaert, K. Moelants, et al. In vitro approaches to estimate the effect of food processing on carotenoid bioavailability need thorough understanding of process induced microstructural changes, Trends Food Sci. Technol., 2010, 21(12), 607-618.

29 J. Jeffery, A. Holzenburg and S. King, Physical barriers to carotenoid bioaccessibility, Ultrastructure survey of chromoplast and cell wall morphology in nine carotenoid-containing fruits and vegetables, J. Sci. Food Agric., 2012, 92(13), 2594-2602.

30 J. L. Jeffery, N. D. Turner and S. R. King, Carotenoid bioaccessibility from nine raw carotenoid-storing fruits and vegetables using an in vitro model, J. Sci. Food Agric., 2012, 92(13), 2603-2610.

31 R. M. Schweiggert, D. Mezger, F. Schimpf, C. B. Steingass and R. Carle, Influence of chromoplast morphology on carotenoid bioaccessibility of carrot, mango, papaya, and tomato, Food Chem., 2012, 135(4), 2736-2742.

32 K. An, D. Zhao, Z. Wang, J. Wu, Y. Xu and G. Xiao, Comparison of different drying methods on Chinese ginger (Zingiber officinale Roscoe): Changes in volatiles, chemical profile, antioxidant properties, and microstructure, Food Chem., 2016, 197, 1292-1300.

33 H. C. P. Karunasena, R. J. Brown, Y. T. Gu and W. Senadeera, Application of meshfree methods to numerically simulate microscale deformations of different plant food materials during drying, J. Food Eng., 2015, 146, 209226.

34 M. L. Rojas and P. E. D. Augusto, Microstructure elements affect the mass transfer in foods: The case of convective drying and rehydration of pumpkin, LWT - Food Sci. Technol., 2018, 93, 102-108.

35 B. G. Smith, B. J. James and C. a. L. Ho, Microstructural Characteristics of Dried Carrot Pieces and Real Time Observations during Their Exposure to Moisture, Int. J. Food Eng., 2007, 3(4), DOI: 10.2202/1556-3758.1242.

36 L. L. Huang, M. Zhang, L. P. Wang, A. S. Mujumdar and D. F. Sun, Influence of combination drying methods on composition, texture, aroma and microstructure of apple slices, LWT - Food Sci. Technol., 2012, 47(1), 183-188.

37 P. P. Lewicki and G. Pawlak, Effect of Drying on Microstructure of Plant Tissue, Drying Technol., 2003, 21, 657. 
38 M. E. Dalmau, G. M. Bornhorst, V. Eim, C. Rosselló and S. Simal, Effects of freezing, freeze drying and convective drying on in vitro gastric digestion of apples, Food Chem., $2017,215$.

39 Ó. Rodríguez, P. Llabrés, S. Simal, A. Femenia and

C. Rosselló, Intensification of Predrying Treatments by Means of Ultrasonic Assistance: Effects on Water Mobility, PPO Activity, Microstructure, and Drying Kinetics of Apple, Food Bioprocess Technol., 2014, 1-13.

40 A. Vega-Gálvez, K. Ah-Hen, M. Chacana, J. Vergara, J. Martínez-Monzó, P. García-Segovia, et al. Effect of temperature and air velocity on drying kinetics, antioxidant capacity, total phenolic content, colour, texture and microstructure of apple (var. Granny Smith) slices, Food Chem., 2012, 132(1), 51-59.

41 C. Ramírez, E. Troncoso, J. Muñoz and J. M. Aguilera, Microstructure analysis on pre-treated apple slices and its effect on water release during air drying, J. Food Eng., 2011, 106(3), 253-261.

42 M. L. Ng and R. Sulaiman, Development of beetroot (Beta vulgaris) powder using foam mat drying, $L W T$ - Food Sci. Technol., 2018, 88, 80-86.

43 S. Van Buggenhout, M. Lille, I. Messagie, A. Van Loey, K. Autio and M. Hendrickx, Impact of pretreatment and freezing conditions on the microstructure of frozen carrots: Quantification and relation to texture loss, Eur. Food Res. Technol., 2006, 222(5-6), 543-553.

44 G. M. Bornhorst, L. Q. Chang, S. M. Rutherfurd, P. J. Moughan and R. P. Singh, Gastric emptying rate and chyme characteristics for cooked brown and white rice meals in vivo, J. Sci. Food Agric., 2013, 93(12), 2900-2908.

45 G. M. Bornhorst, M. J. Roman, K. C. Dreschler and R. P. Singh, Physical Property Changes in Raw and Roasted Almonds during Gastric Digestion In vivo and In vitro, Food Biophys., 2014, 9, 39-48.

46 D. Chandra, A. E. Choi, Y. P. Kim and J. I. G. Kim, Paper physicochemical, microbial and sensory quality of fresh-cut red beetroots in relation to sanitization method and storage duration, Ital. J. Food Sci., 2015, 27, 208-220.

47 Y. A. Mennah-Govela and G. M. Bornhorst, Acid and moisture uptake in steamed and boiled sweet potatoes and associated structural changes during in vitro gastric digestion, Food Res. Int., 2016, 88(Part B), 247-255.

48 T. S. Kujala, J. M. Loponen, K. D. Klika and K. Pihlaja, Phenolics and betacyanins in red beetroot (Beta vulgaris) root: distribution and effect of cold storage on the content of total phenolics and three individual compounds, J. Agric. Food Chem., 2000, 48(11), 5338-5342.

49 R. P. F. Guiné, F. Henriques and M. J. Barroca, Influence of drying treatments on the physical and chemical properties of cucumber, J. Food Meas. Charact., 2014, 8(3), 195-206.

50 A. Vega-Gálvez, K. Di Scala, K. Rodríguez, R. LemusMondaca, M. Miranda, J. López, et al. Effect of air-drying temperature on physico-chemical properties, antioxidant capacity, colour and total phenolic content of red pepper
(Capsicum annuum, L. var. Hungarian), Food Chem., 2009, 117(4), 647-653.

51 D. Ferreira, S. Guyot, N. Marnet, I. Delgadillo, C. M. Renard and M. A. Coimbra, Composition of Phenolic Compounds in a Portuguese Pear (Pyrus communis L. Var. S. Bartolomeu) and Changes after Sun-Drying, J. Agric. Food Chem., 2002, 50(16), 4537-4544.

52 D. K. Asami, Y. J. Hong, D. M. Barrett and A. E. Mitchell, Comparison of the total phenolic and ascorbic acid content of freeze fried and air dried marionberry, strawberry, and corn grown using conventional, organic, and sustainable agricultural practices, J. Agric. Food Chem., 2003, 51, 1237-1241.

53 M. R. González-Centeno, M. Jourdes, A. Femenia, S. Simal, C. Rosselló and P.-L. Teissedre, Proanthocyanidin Composition and Antioxidant Potential of the Stem Winemaking Byproducts from 10 Different Grape Varieties (Vitis vinifera L.), J. Agric. Food Chem., 2012, 60, 1185011858.

54 T. Sawicki and W. Wiczkowski, The effects of boiling and fermentation on betalain profiles and antioxidant capacities of red beetroot products, Food Chem., 2018, 259, 292-303.

55 V. Raikos, A. McDonagh, V. Ranawana and G. Duthie, Processed beetroot (Beta vulgaris L.) as a natural antioxidant in mayonnaise: Effects on physical stability, texture and sensory attributes, Food Sci. Hum. Wellness, 2016, 5(4), 191-198.

56 A. Loncaric, K. Dugalic, I. Mihaljevic, L. Jakobek and V. Pilizota, Effects of Sugar Addition on Total Polyphenol Content and Antioxidant Activity of Frozen and FreezeDried Apple Puree, J. Agric. Food Chem., 2014, 62, 16741682.

57 J. Bouayed, L. Hoffmann and T. Bohn, Total phenolics, flavonoids, anthocyanins and antioxidant activity following simulated gastro-intestinal digestion and dialysis of apple varieties: Bioaccessibility and potential uptake, Food Chem., 2011, 128(1), 14-21.

58 S. Kamiloglu, A. A. Pasli, B. Ozcelik, J. Van Camp and

E. Capanoglu, Influence of different processing and storage conditions on in vitro bioaccessibility of polyphenols in black carrot jams and marmalades, Food Chem., 2015, 186, 74-82.

59 J. Chen, H. Sun, Y. Wang, S. Wang, X. Tao and A. Sun, Stability of Apple Polyphenols as a Function of Temperature and pH, Int. J. Food Prop., 2014, 17(8), 1742-1749.

60 P. C. Wootton-Beard and L. Ryan, A beetroot juice shot is a significant and convenient source of bioaccessible antioxidants, J. Funct. Foods, 2011, 3(4), 329-334.

61 M. Fazzari, L. Fukumoto, G. Mazza, M.A Livrea, L. Tesoriere and L.D. Marco, In vitro bioavailability of phenolic compounds from five cultivars of frozen sweet cherries (Prunus avium L.), J. Agric. Food Chem., 2008, 56(10), 3561-3568.

62 A. Pérez-Vicente, A. Gil-Izquierdo and C. García-Viguera, In Vitro Gastrointestinal Digestion Study of Pomegranate 
Juice Phenolic Compounds, Anthocyanins, and Vitamin C, J. Agric. Food Chem., 2002, 50(8), 2308-2312.

63 M. J. Rodríguez-Roque, B. de Ancos, C. Sánchez-Moreno, M. P. Cano, P. Elez-Martínez and O. Martín-Belloso, Impact of food matrix and processing on the in vitro bioaccessibility of vitamin $\mathrm{C}$, phenolic compounds, and hydrophilic antioxidant activity from fruit juice-based beverages, J. Funct. Foods, 2015, 14, 33-43.
64 A. Cilla, S. Perales, M. J. Lagarda, R. Barberá, G. Clemente and R. Farré, Influence of storage and in vitro gastrointestinal digestion on total antioxidant capacity of fruit beverages, J. Food Compos. Anal., 2011, 24(1), 87-94.

65 J. Pérez-Jiménez and F. Saura-Calixto, Effect of solvent and certain food constituents on different antioxidant capacity assays, Food Res. Int., 2006, 39(7), 791800 . 